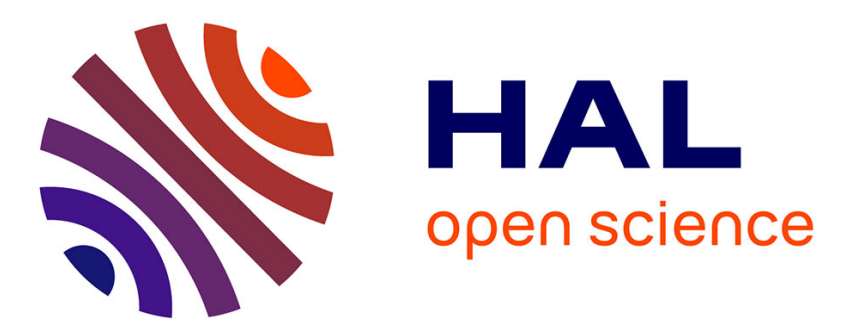

\title{
Nuclear Magnetic Resonance (NMR) Characterization of a Polymerized Ionic Liquid Electrolyte Material
}

\author{
A.L. L Michan, G.T.M. T M Nguyen, O. Fichet, F. Vidal, Cedric \\ Vancaeyzeele, C.A. A Michal
}

\section{To cite this version:}

A.L. L Michan, G.T.M. T M Nguyen, O. Fichet, F. Vidal, Cedric Vancaeyzeele, et al.. Nuclear Magnetic Resonance (NMR) Characterization of a Polymerized Ionic Liquid Electrolyte Material. MRS Online Proceedings Library, 2012, 1440, 10.1557/opl.2012.1280 . hal-03282880

\section{HAL Id: hal-03282880 \\ https://hal.science/hal-03282880}

Submitted on 9 Jul 2021

HAL is a multi-disciplinary open access archive for the deposit and dissemination of scientific research documents, whether they are published or not. The documents may come from teaching and research institutions in France or abroad, or from public or private research centers.
L'archive ouverte pluridisciplinaire HAL, est destinée au dépôt et à la diffusion de documents scientifiques de niveau recherche, publiés ou non, émanant des établissements d'enseignement et de recherche français ou étrangers, des laboratoires publics ou privés. 


\title{
Nuclear Magnetic Resonance (NMR) Characterization of a Polymerized Ionic Liquid Electrolyte Material
}

\author{
A.L. Michan ${ }^{1}$, G.T.M. Nguyen ${ }^{2}$, O. Fichet ${ }^{2}$, F. Vidal ${ }^{2}$, C. Vancaeyzeele ${ }^{2}$ C.A. Michal ${ }^{1}$ \\ ${ }^{1}$ Physics and Astronomy, University of British Columbia, Vancouver, BC, Canada. \\ ${ }^{2}$ Laboratoire de Physicochimie des Polymères et des Interfaces (LPPI), Institut des Matériaux, \\ University of Cergy-Pontoise, France.
}

\begin{abstract}
Solid electrolyte materials have the potential to improve performance and safety characteristics of lithium-ion batteries by replacing conventional solvent-based electrolytes. A candidate solid polymer electrolyte, AMLi/PEGDM, has been synthesized by crosslinking an anionic monomer AMLi, with poly(ethylene glycol) dimethacrylate. The main goal of the synthesis is to produce a single-ion conducting polymer network where lithium cations can move freely and fluorinated anions are immobilized as part of the polymer network. A comprehensive characterization of anion and cation mobility in the resulting material is therefore required. Using pulsed-field gradient nuclear magnetic resonance (PFG-NMR), we are able to measure and quantify the individual diffusion coefficients of mobile species in the material $\left({ }^{19} \mathrm{~F}\right.$ and $\left.{ }^{7} \mathrm{Li}\right)$ and confirm the extent to which the fluorinated anionic component is immobilized. We have characterized dry $\left(\sigma \sim 3.0 \times 10^{-7} \mathrm{~S} / \mathrm{cm}\right.$ at $\left.30^{\circ} \mathrm{C}\right)$ and propylene carbonate $(\mathrm{PC})$ saturated gel $\left(\sigma \sim 1.0 \times 10^{-4} \mathrm{~S} / \mathrm{cm}\right.$ at $\left.30^{\circ} \mathrm{C}\right)$ samples. Experimental results include NMR spin-spin and spin-lattice relaxation times in addition to diffusion coefficient measurements over a temperature range up to $100^{\circ} \mathrm{C}$. Practically, the diffusion measurements are extremely challenging, as the spin-spin $\left(\mathrm{T}_{2}\right)$ relaxation times are very short, necessitating the development of specialized pulsed-field gradient apparatus. Diffusion coefficients for the most mobile components of the lithium cations and fluorinated anions at $100^{\circ} \mathrm{C}$ in dry membranes have been found to be $3.4 \times 10^{-8} \mathrm{~cm}^{2} / \mathrm{s}$ and 2.1 $\mathrm{x} 10^{-8} \mathrm{~cm}^{2} / \mathrm{s}$ respectively. These results provide valuable insight into the conduction mechanisms in these materials, and will drive further optimization of solid polymer electrolytes.
\end{abstract}

\section{INTRODUCTION}

Solid polymer membranes have the potential to improve lithium-ion battery safety by replacing conventional liquid electrolytes with a relatively non-volatile alternative. During battery cell operation, concentration gradients develop as lithium cations shuttle between the electrodes and across the electrode/electrolyte interfaces. Mobile anions can accumulate and take part in unwanted side reactions, impeding current flow [1]. Single-ion conductive polymers are therefore expected to deliver more current than bi-ionic conductors.

A candidate solid polymer electrolyte, AMLi/PEGDM, has been synthesized by crosslinking an anionic monomer AMLi, Fig 1, with poly(ethylene glycol) dimethacrylate (PEGDM, M=750 g/mol) by free-radical polymerization initiated with AIBN in ethanol. The AMLi lithium pair of the anionic monomer (AMLi) was synthesized using the precursor AMH, described previously [2]. The networks were abbreviated as AMLi/PEGDM X/Y, with X and Y representing the AMLi monomer and PEGDM weight proportions, respectively. The synthesis is aimed at producing a single-ion conducting polymer network where lithium cations can move 
freely and fluorinated anions are immobilized as part of the polymer network. It is thought that ionic motion occurs by intra- and inter-chain hopping in the crosslinked polymer matrix.

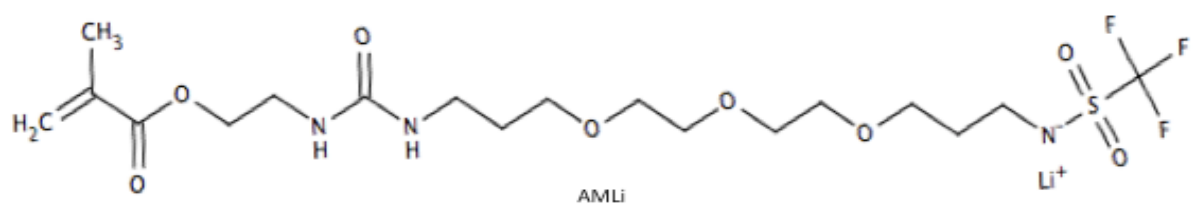

Figure 1: AMLi Monomer

Using pulsed-field gradient nuclear magnetic resonance (PFG-NMR), we are able to measure the individual diffusion coefficients of mobile species in the material $\left({ }^{19} \mathrm{~F}\right.$ and $\left.{ }^{7} \mathrm{Li}\right)$ and quantify the amount of each ionic component diffusing. Using these results, we can confirm the extent to which the fluorinated anionic component is immobilized. Additionally, we have measured the longitudinal $\left(\mathrm{T}_{1}\right)$ and spin-spin $\left(\mathrm{T}_{2}\right)$ relaxation times.

\section{EXPERIMENT}

A pulsed-field-gradient stimulated echo (PFGSE) [3] sequence was used to measure diffusion coefficients. The stimulated echo sequence allows for longer diffusion times by storing the nuclear spin magnetization along the z-axis, subject to $T_{1}$ relaxation in contrast to faster $T_{2}$ relaxation. As the $T_{2}$ relaxation times are especially short in the solid dry material, and the diffusion coefficients are relatively slow, the applied gradient pulses must be extremely short and intense. The sinusoidal shaped gradient pulse was applied for a total of $\sim 300 \mu$ s with a maximum amplitude of $\sim 3100 \mathrm{G} / \mathrm{cm}$, using a resonant gradient driver [4,5] and home-built NMR spectrometer operating at $8.4 \mathrm{~T}[6]$.

In addition to performing standard diffusion coefficient measurements, we were able to quantify the number of ions diffusing. To accomplish this, relaxation times causing exponential signal intensity decay during the PFGSE experiment were accounted for. Delay times in the PFGSE sequence were varied in order to measure relaxation in the context of the diffusion experiment. The diffusion experiments were simultaneously fit, with the two exponential decay factors due to the relaxation times multiplied by the standard PFGSE Gaussian decay for a sinusoidal gradient pulse [7]. In the case of two-component relaxation and diffusion times, the two components were handled separately, with coefficients corresponding to the amount of each component diffusing. Furthermore, calibration factors were found using the same method with samples of known weight and composition. We were then able to quantify the numbers of fluorinated anions and lithium cations diffusing in each sample. The method was validated using two reference samples PEGM/PEGDM LiTFSI (Bis(trifluoromethane)sulfonimide lithium salt) where the fluorinated anions and lithium cations can move freely and were expected in a 1:1 ratio. Finally, an AMLi sample was measured in its dry and propylene carbonate (PC) saturated state.

The ionic conductivity $\sigma_{\mathrm{EXP}}$ was measured by AC impedance spectroscopy (VSP, Biologic) in the frequency range from $1 \mathrm{MHz}$ to $1 \mathrm{~Hz}$ with an oscillation potential of $10 \mathrm{mV}$. The polymer film was sandwiched between two stainless steel electrodes, and measurements were performed under argon atmosphere up to $120^{\circ} \mathrm{C}$. 
The measured conductivities were compared to values based on the NMR measurements computed from the Nernst-Einstein equation,

$$
\Lambda_{N M R}=\frac{\sigma_{N M R}}{C}=\frac{N_{A} e^{2}}{k T}\left(D_{+}+D_{-}\right)
$$

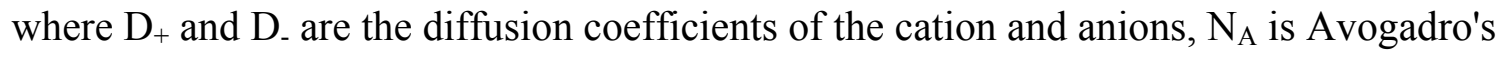
number, $\mathrm{C}$ is the molar concentration of ions, $\mathrm{k}$ is Boltzmann's constant, $\mathrm{e}$ is the electron charge and $\mathrm{T}$ is the temperature. This equation describes conductivity in dilute solutions where anions and cations are fully dissociated. The ratio of measured conductivity to that calculated with the Nernst-Einstein equation can be used as a rough approximation of the degree of dissociation in the material $[8,9]$. Reduced dissociation indicates ion pairing or clustering and results in a reduction in the number of effective charge carriers.

\section{RESULTS \& DISCUSSION}

The ${ }^{19} \mathrm{~F}$ and ${ }^{7} \mathrm{Li}$ diffusion coefficients of the dry sample AMLi/PEGDM 40/60 were measured at $100^{\circ} \mathrm{C}$ by fitting PFGSE signal attenuation, in Fig 2 . The cation and anion diffusion coefficients of $3.4 \times 10^{-8} \mathrm{~cm}^{2} / \mathrm{s}$ and $2.1 \times 10^{-8} \mathrm{~cm}^{2} / \mathrm{s}$ were on the same order, confirming both lithium cations and fluorinated anions were mobile in the sample. Using the Nernst-Einstein equation gave an approximate conductivity $\sigma_{\mathrm{NMR}}$ of $1.5 \times 10^{-4} \mathrm{~S} / \mathrm{cm}$ in contrast to the experimentally observed conductivity $\sigma_{\mathrm{EXP}}$ of $1.0 \times 10^{-5} \mathrm{~S} / \mathrm{cm}$ at $100^{\circ} \mathrm{C}$. From the ratio $\sigma_{\mathrm{EXP}}$ $/ \sigma_{\mathrm{NMR}}$ we approximate a dissociation of $\sim 6 \%$. These results suggested correlated diffusion. Diffusion was not observed in dry samples at room temperature, although the experimental limit was on the order of $\sim 1 \times 10^{-9} \mathrm{~cm}^{2} / \mathrm{s}$ and it is possible diffusion was present with a slower rate.

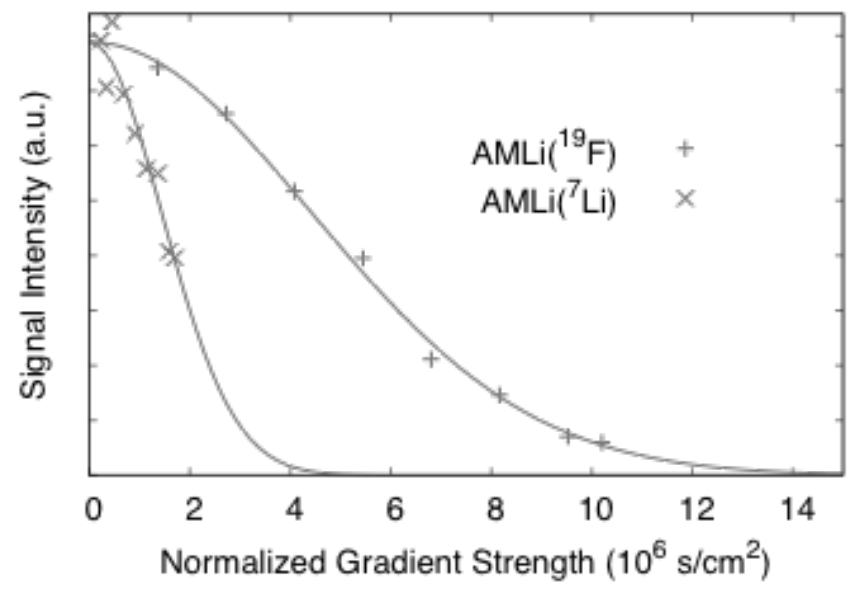

Figure 2: Experimental PFGSE data and diffusion coefficient fits for AMLi/PEGDM 40/60 at $100^{\circ} \mathrm{C}$ with a diffusion time $\Delta$ of $0.5 \mathrm{~s}$. The $\mathrm{x}$-axis is normalized for the diffusion time $\Delta$, gradient pulse duration $\delta$, and gyromagnetic ratio $\gamma$.

Measurements at room temperature were performed on AMLi/PEGDM X/Y samples saturated with PC, summarized in Table I. Two-component diffusion was observed in the case of fluorine, while the lithium diffusion data was adequately described by a single component. The presence of additional ${ }^{19} \mathrm{~F}$ and ${ }^{7} \mathrm{Li}$ diffusion coefficients arising from components with short $\mathrm{T}_{1}$ 
$(<200 \mathrm{~ms})$ and/or $\mathrm{T}_{2}$ times $(<0.5 \mathrm{~ms})$ cannot be ruled out, as they would be strongly suppressed in the PFGSE diffusion experiment. The two-component anion diffusion suggests some immobilization of the fluorine, with the first component diffusing an order of magnitude slower than the second component. The second fluorinated anionic diffusion coefficient $\left({ }^{19} \mathrm{~F} \mathrm{D}_{\mathrm{B}-}\right)$ is of similar magnitude to the lithium diffusion coefficient $\left({ }^{7} \mathrm{Li} \mathrm{D}_{+}\right)$, suggesting correlated diffusion. Thus, the fluorinated anions were not completely immobilized in a crosslinked network.

Table I: Summary of diffusion coefficients measured in PC saturated AMLi X/Y samples

\begin{tabular}{|c|c|c|c|}
\hline $\begin{array}{c}\text { AMLi/PEGDM X/Y } \\
\text { Samples }\end{array}$ & $\begin{array}{c}{ }^{7} \mathrm{Li} \mathrm{D} \mathrm{D}_{+}\left(\mathrm{cm}^{2} / \mathrm{s}\right) \\
(\Delta=350 \mathrm{~ms})\end{array}$ & $\begin{array}{c}{ }^{19} \mathrm{~F} \mathrm{D}_{\mathrm{A}-} / \mathrm{D}_{\mathrm{B}-}\left(\mathrm{cm}^{2} / \mathrm{s}\right) \\
(\Delta=500 \mathrm{~ms})\end{array}$ & $\begin{array}{c}\text { Abundance Ratio } \\
\text { (A/B) }\end{array}$ \\
\hline AMLi/PEGDM 50/50 & $9.8 \times 10^{-7}$ & $3.0 \times 10^{-7} / 1.7 \times 10^{-6}$ & $3: 1$ \\
\hline AMLi/PEGDM 70/30 & $1.3 \times 10^{-6}$ & $4.5 \times 10^{-7} / 3.1 \times 10^{-6}$ & $3: 2$ \\
\hline AMLi/PEGDM 80/20 & $1.0 \times 10^{-6}$ & $3.1 \times 10^{-7} / 2.2 \times 10^{-6}$ & $3: 3$ \\
\hline
\end{tabular}

Based on the two-component nature of the diffusion results in the saturated samples (Table I), samples were extracted in ethanol. Analysis of the obtained product indicated the presence of side reactions appearing during the polymerization in ethanol that could prevent the formation of fully crosslinked material. For subsequent samples the synthesis was modified, using THF instead of ethanol. After optimization, DiCyclohexyl PeroxydiCarbonate (DCPD) was added as a replacement for AIBN. The new samples AMLi/PEGDM with lower content of AMLi showed negligible extractable component. Upon measuring diffusion coefficients of AMLi/PEGDM 20/80 (w/DCPD), two-component anion diffusion was again observed.

The quantification method described in the experimental section above, accounting for relaxation during the PFGSE sequence, was employed to determine the abundance of mobile anions and cations. In order to validate the technique, reference samples of PEGM/PEGDM/ LiTFSI with the same numbers of ions as in the AMLi/PEGDM 20/80 network were tested in a dry and PC saturated state. The results are summarized in Table II.

Table II: Summary of PEGM/PEGDM/LiTFSI, abundance of cationic and anionic components diffusing

\begin{tabular}{lccc}
\multicolumn{1}{c}{ Sample } & $N_{L i}$ (mols) & $N_{F_{6}}$ (mols) & $N_{L i}: N_{F_{6}}$ \\
\hline PEGM/PEGDM/LiTFSI (dry) (373K) & $6.8 \times 10^{-5}$ & $5.9 \times 10^{-5}$ & $1: 1$ \\
PEGM/PEGDM/LiTFSI (w/PC) (298K) & $7.6 \times 10^{-5}$ & $7.0 \times 10^{-5}$ & $1: 1$
\end{tabular}

The total number of lithium cations (1/salt molecule) and fluorinated ions (6/salt molecule) were in qualitative agreement with the expected numbers of $4.0 \times 10^{-5}$ mols (dry) and $4.4 \times 10^{-5}$ mols (w/PC), based on the samples' compositions. The measured numbers of ions diffusing in these samples included a correction factor to account for the fact that a significant fraction of the sample protruded outside of the NMR coil. Uncertainty in the correction factor likely accounts for the remaining discrepancy (x1.5) between the measured and expected values. Future work would incorporate more uniform sample sizes for increased accuracy, although the overall agreement was satisfactory and the consistency between the results found with the two different nuclear species inspires confidence in the technique.

Finally, the quantification technique was applied to an AMLi/PEGDM 20/80 (w/DCPD) sample. Results are summarized in Table III. The measured quantities of fluorinated and lithium ions diffusing were unexpected. The amount of AMLi monomer expected based on weight and 
composition was $5.8 \times 10^{-6}$ mols. However, the quantification experiments found roughly four times more ${ }^{19} \mathrm{~F}$ but only half the ${ }^{7} \mathrm{Li}$ expected. As our experimental technique has been validated with the (LiTFSI) reference samples, these results reflect some unknown result of our synthesis method.

Table III: Summary of AMLi/PEGDM 20/80 (w/DCPD) diffusion coefficients and number of ions diffusing. A and $\mathrm{B}$ represent two components.

\begin{tabular}{|c|c|c|c|c|c|c|c|}
\hline \multicolumn{2}{|c|}{$\begin{array}{l}\text { AMLi/PEGDM 20/80 } \\
\text { (w/DCPD) Sample }\end{array}$} & $\begin{array}{c}{ }^{7} \mathbf{L i ~} \mathrm{D}_{+}\left(\mathrm{cm}^{2} / \mathrm{s}\right) \\
(\Delta=350 \mathrm{~ms})\end{array}$ & $\begin{array}{c}{ }^{19} \mathrm{~F} \mathrm{D} \mathrm{D}_{-}\left(\mathrm{cm}^{2} / \mathrm{s}\right) \\
(\Delta=1000 \mathrm{~ms})\end{array}$ & $\begin{array}{c}N_{L i} \\
\text { (mols) }\end{array}$ & $\begin{array}{c}N_{F_{3}} \\
\text { (mols) }\end{array}$ & $\begin{array}{c}N_{F_{3}} \\
\text { Ratio A/B }\end{array}$ & $N_{L i}: N_{F_{3}}$ \\
\hline \multirow{2}{*}{ Dry $(373 K)$} & A & $2.0 \times 10^{-8}$ & $2.4 \times 10^{-8}$ & $2 \times 10^{-6}$ & $1.5 \times 10^{-5}$ & \multirow{2}{*}{2.3} & \multirow{2}{*}{$1: 10$} \\
\hline & B & & $1.9 \times 10^{-9}$ & & $6.3 \times 10^{-6}$ & & \\
\hline
\end{tabular}

The two-component behavior of the ${ }^{19} \mathrm{~F}$ diffusion measurements was in agreement with the corresponding relaxation measurements. The first anionic component had an almost identical diffusion coefficient to $\mathrm{Li}^{+}$of $\sim 2 \times 10^{-8} \mathrm{~cm}^{2} / \mathrm{s}$, suggesting highly correlated diffusion. The second anionic diffusion coefficient of $1.9 \times 10^{-9} \mathrm{~cm}^{2} / \mathrm{s}$ is an order of magnitude less, suggesting this component is less mobile in the polymer network. A corresponding component for ${ }^{7} \mathrm{Li}$ was not observed but may be present with a $\mathrm{T}_{2}$ time too short or diffusion coefficient too low to be observed. Quantitative ${ }^{7} \mathrm{Li}$ measurements of the sample in the PC saturated state agreed with the dry state measurements, with the diffusion coefficient $1.75 \times$ larger, $3.5 \times 10^{-8} \mathrm{~cm}^{2} / \mathrm{s}$.

Comparable dry samples of AMLi/PEGDM 40/60 and AMLi/PEGDM 50/50 had a measured conductivity of $\sim 1 \times 10^{-5} \mathrm{~S} / \mathrm{cm}$ compared with conductivity estimated from the NMR measurements $\sigma_{\mathrm{NMR}}$ of $1.0 \times 10^{-4} \mathrm{~S} / \mathrm{cm}$ at $100^{\circ} \mathrm{C}$. Comparing these conductivities suggests a dissociation of $\sim 10 \%$. Further work is therefore required to fully immobilize the fluorinated anions in a crosslinked network and several additional samples are under investigation.

\section{CONCLUSIONS}

A solid polymer material AMLi/PEGDM was synthesized, with the goal of immobilizing fluorinated anions in a crosslinked network. Measurements of ${ }^{19} \mathrm{~F}$ and ${ }^{7} \mathrm{Li}$ diffusion coefficients in the dry and saturated polymer samples show correlated anion and cation diffusion. The fluorinated anions were not fully immobilized, suggested by two-component diffusion coefficients and relaxation times. Using PFGSE NMR we were able to quantify the number of ions diffusing in our dry solid polymer samples demonstrating a viable technique for probing diffusion coefficients.

\section{ACKNOWLEDGMENTS}

This work was supported by a Discovery Grant from the Natural Sciences and Engineering Research Council of Canada.

\section{REFERENCES}

1. H. Mazor, D. Golodnitsky, E. Peled, W. Wieczorek and B. Scrosati, J. of Power Sources 178, 736-743 (2008).

2. J. Juger, F. Meyer, F. Vidal, C. Chevrot, D. Teyssie, Tetrahedron Letters 50, 128-131 (2009). 
3. J.E. Tanner, J. of Chemical Physics, 52, 5, 2523-2526 (1970).

4. M.S. Conradi, A.N. Garroway, D.H. Cory, and J.R. Miller, J. Magn. Reson. 94 370-375 (1991).

5. W. Zhang and D.G. Cory, J. of Magnetic Resonance 132, 144-149 (1998).

6. C. A. Michal and K. Broughton and E. Hansen, Review of Scientific Instruments 73, 453458 (2002).

7. J. Mattiello, P.J. Basser and D. LeBihan, J. Mag Reson. Series A 108, 131-141 (1994).

8. M.B. Armand, P.G. Bruce, M. Forsyth, B. Scrosati and W. Wieczorek in Energy Materials edited by D.W. Bruce, D. O'Hare and R.I. Walton (John Wiley \& Sons, Ltd, Chichester, West Sussex, 2011) pp 15.

9. C. Chauvin, F. Alloin, P. Judeinstein, D. Foscallo, and J.-Y. Sanchez, Electrochimica Acta 52, 1240-1246 (2006). 